\title{
A Prospective Clinicoendoscopic Follow-up Study in Young Patients with Peptic Ulcer Perforation at a Tertiary Institute in Central India
}

\author{
Deepa Jahagirdaar ${ }^{1}$, Nitin Bomanwar ${ }^{2}$, Sneha Joshi $^{3}$
}

\begin{abstract}
Background: Perforation peritonitis is one of the commonest encountered emergencies in the surgery casualty. This study was conducted with the aim of identifying risk factors in peptic ulcer disease (PUD) in young patients.

Materials and methods: Seventy patients were evaluated in this study and were followed up with clinical examination and endoscopy at 8 weeks and 6 months.

Results: Out of the total 70 patients, there was a mortality of 5 patients and 7 patients were lost to follow-up. Out of the remaining 57 patients, 56 were men and 1 was a woman. Maximum patients were from the age group of 35-40 years. The patients were categorized on the basis of their clinical symptoms and endoscopy results at the follow-up of 6 months in 4 categories-21 patients having an active ulcer and symptomatic, 15 patients having active ulcer but no symptoms, 16 patients who were asymptomatic and without an active ulcer and 5 patients nonulcer dyspepsia. Conclusion: Postoperative treatment with $\mathrm{H}_{2}$ blockers or proton pump inhibiters along with anti-Helicobacter pylori regimen should be prescribed for all patients with peptic ulcer perforation. Routine endoscopic examination of such patients should also form a part of the follow-up to look for ulcer healing postoperatively.

Keywords: Endoscopy, Helicobacter pylori, Peptic, Perforation, Ulcer.

Euroasian Journal of Hepato-Gastroenterology (2019): 10.5005/jp-journals-10018-1306
\end{abstract}

\section{INTRODUCTION}

Peptic ulcer disease (PUD) occurs in young and old patients all over the world and its management remains a real challenge to the medical profession. The incidence and prevalence of duodenal ulcers has decreased in the last four decades in western countries. ${ }^{1}$ In India, according to the frequency of occurrence, peptic ulcer perforation is the second most common acute abdominal surgical emergency after acute appendicitis. ${ }^{2}$ There is a changing scene with perforated peptic ulcer in terms of clinical presentation and management. Older age of the presentation, increased association with nonsteroidal antiinflammatory drugs (NSAIDs), associated increased morbidity, the resulting higher mortality in elderly is making people rethink the management protocol. ${ }^{3}$ Years ago, most discussion was on whether urgent definitive surgery is most effective therapy; nowadays, there is a tendency to have less invasive procedure and measure. A "deliberate approach," where not in all patients require definitive surgery is detailed and this may lead to increasing role for laparoscopic perforation sealing techniques. Antisecretory and antihelicobacter drugs have an important role in postoperative care following few procedures than definitive surgery. ${ }^{3}$

The present study was done with the following aims and objectives:

- The aim of the present study was to study the various risk factors for PUD and perforation in young patients.

- Role of follow-up endoscopy.

- Role of Helicobacter pylori eradication in preventing ulcer relapse.

\section{Materials and Methods}

In this study of peptic ulcer perforation in young patients (12-40 years), those who attended surgery out patient department

\footnotetext{
${ }^{1,3}$ Department of General Surgery, Government Medical College and Hospital, Nagpur, Maharashtra, India

${ }^{2}$ Department of Surgical Oncology, Kingsway Hospitals, Nagpur, Maharashtra, India

Address reprint requests to: Nitin Bomanwar, Department of Surgical Oncology, Kingsway Hospitals, Nagpur, Maharashtra, India, Phone: +91 9909021131, e-mail: bomanwarnitin@yahoo.in

How to cite this article: Jahagirdaar D, Bomanwar N, Joshi S. A Prospective Clinicoendoscopic Follow-up Study in Young Patients with Peptic Ulcer Perforation at a Tertiary Institute in Central India. Euroasian J Hepato-Gastroenterol 2019;9(2):91-95.

Source of support: Nil

Conflict of interest: None
}

(OPD)/casualty department of a tertiary care center in central India were included. A total of 70 young patients were evaluated having peptic ulcer perforation. The diagnosis of peptic perforation was made on the basis of clinical history, detailed clinical examination, radiologic and operative findings. Emergency laparoscopic suturing of peptic perforation was not performed as facility to use laparoscope was available only for elective laparoscopic procedures.

Each patient was studied and stress was given on the identification and recording of various predictors of ulcer healing in postoperative follow-up endoscopy.

\section{Study Design}

It was a tertiary center-based prospective longitudinal cohort study conducted between December 2015 and October 2017. 


\section{Inclusion Criteria}

Young patients in the age group of 12-40 years of age having PUD and perforation attending OPD/casualty in tertiary care center in central India between December 2015 and October 2017.

\section{Exclusion Criteria}

Following patients were excluded from the study:

- Causes of dyspepsia other than peptic ulcer;

- Proven malignant perforation;

- Multiple endocrinal adenopathy with perforation; and

- Anastomotic ulcer perforation.

\section{Outcome Factors}

Patients who were clinically symptomatic and having an active ulcer on endoscopy were the chief outcome.

\section{Methodology}

For all patients with perforated peptic ulcer, attending team belonged to the general surgical units.

The general plan of approach was as follows:

- Preliminary evaluation to ascertain urgent need of the patients' resuscitation;

- Detailed physical examination;

- Nasogastric aspiration; and

- Radiologic examination: abdominal X-ray erect (Fig. 1).

All patients with peptic perforation were taken for emergency exploratory laparotomy. Intraoperatively site, number, local findings (fibrosis and induration) were noted (Fig. 2), and perforation was closed with simple sutures with omental patch (Graham's technique) with thorough peritoneal lavage.

All patients were evaluated in the postoperative period for different study factors and were kept on antiulcer treatment/H. pylori eradication.

All these patients were followed up clinically and endoscopically at 8 weeks and 6 months interval and findings were noted. All patients on discharge from the hospital were given instructions about diet and medication. Patients were regularly advised about nonsmoking, alcohol abstinence, and avoiding drugs such as NSAIDs and modification of dietary habits. Patients were followed up in surgery OPD initially and subsequently in Gastroenterology OPD in Super Specialty Hospital. In follow-up cases, endoscopic

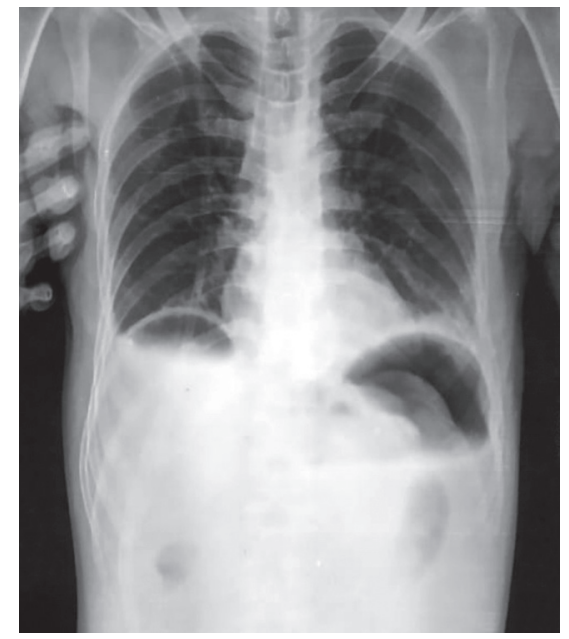

Fig. 1: X-ray abdomen erect showing gas under diaphragm examination was performed in the endoscopic unit using gastrointestinal fiberscope (Pentax, Japan).

The pylorus was examined for its position, shape, and presence of edema, hyperemia, and pattern of gastric peristalsis. The second, third part of the duodenum was also routinely inspected except in patients with stenosis. While removing the instrument, the organs were again examined in a retrograde fashion. In patients with stenosis, spasm of the pylorus, hypersecretion and hyperperistalsis of stomach, intravenous buscopan 3cc was used to relax the organ.

Clinically, patients were categorized into three groups according to the severity of symptoms:

- Satisfactory well,

- mild dyspepsia, and

- severe symptoms.

A co-relation between clinical and endoscopic findings was performed with relation to various factors affecting ulcer healing.

\section{Results and Observation}

The present study evaluated 70 patients with peptic ulcer perforation between the age group of 12-40 years. Out of those patients, there was a mortality of five patients in the postoperative period and eight patients were lost to follow-up. Out of the remaining 57 patients, 56 were men and 1 was a woman. Demographics of the patients are presented in Table 1.

The youngest patient in the study was a male with an age of 15 years and the eldest as 40-year-old male. Only one female of age 25 years was evaluated in the study. The highest incidence of perforation was seen in the age group of 36-40 years (18 patients). As such, a male preponderance was seen in the study.

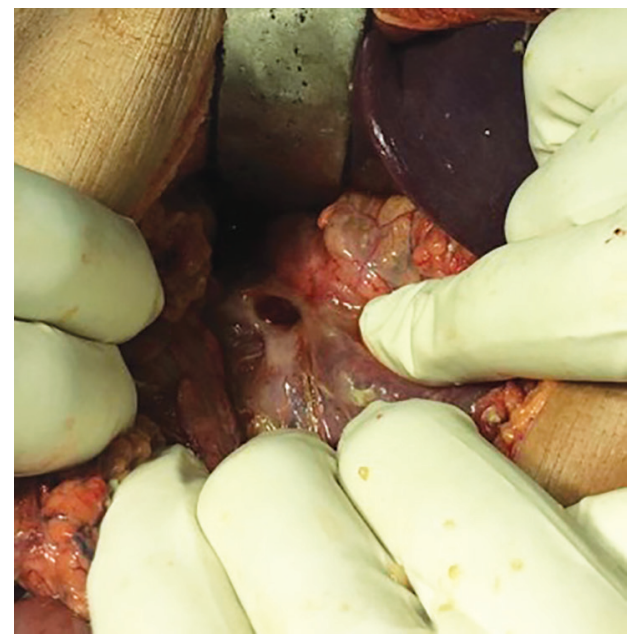

Fig. 2: Gastric perforation site

Table 1: Demographics of study population

\begin{tabular}{llll}
\hline $\begin{array}{l}\text { Age group } \\
\text { in years }\end{array}$ & $\begin{array}{l}\text { Number of } \\
\text { female patients }\end{array}$ & $\begin{array}{l}\text { Number of } \\
\text { male patients }\end{array}$ & $\begin{array}{l}\text { Total number } \\
\text { of patients }\end{array}$ \\
\hline $12-15$ & 0 & 2 & 2 \\
$16-20$ & 0 & 7 & 7 \\
$21-25$ & 1 & 4 & 5 \\
$26-30$ & 0 & 13 & 13 \\
$31-35$ & 0 & 12 & 12 \\
$36-40$ & 0 & 18 & 18 \\
Total & 1 & 56 & 57 \\
\hline
\end{tabular}


On the basis of intraoperative findings, there was gastric perforation in seven patients and the rest were pyloro-duodenal ulcer perforation. Table 2 shows the distribution of site of peptic ulcer perforation.

The patients were followed up at 8 weeks and 6 months and given antiulcer and $H$. pylori eradication treatment. On follow-up, a detailed clinical examination was performed followed by endoscopy. Depending on the symptomatology at 6 months follow-up, patients were categorized as satisfactorily well, having mild dyspepsia and having severe symptoms (Table 3 ).

The patients were subjected to endoscopy at 8 weeks and 6 months postoperatively, and the results are summarized in Table 4 .

After 8 weeks postoperatively, 30 patients (52.6\%) had no ulcer on endoscopy out of which 24 patients $(80 \%)$ were on treatment and $6(20 \%)$ were not on any treatment. The remaining 27 patients (47.4\%) had active ulcer and other positive endoscopic findings out of which 16 patients (59.2\%) were on treatment and 11 patients $(41.8 \%)$ were not on any treatment.

After 6 months postoperatively, 36 patients (63.1\%) had no ulcer on endoscopy out of which 27 (75\%) were on treatment and $9(25 \%)$ were without treatment. The remaining 21 patients $(29.1 \%)$ had some positive endoscopic finding out of which 13 (61.9\%) were on treatment and 8 (38.1\%) were without treatment.

Table 2: Distribution of site of perforation

\begin{tabular}{|c|c|c|c|c|}
\hline Site & & $\begin{array}{l}\text { Number of } \\
\text { patients }\end{array}$ & $\begin{array}{l}\text { Number } \\
\text { of male } \\
\text { patients }\end{array}$ & $\begin{array}{l}\text { Number } \\
\text { of female } \\
\text { patients }\end{array}$ \\
\hline \multirow{2}{*}{$\begin{array}{l}\text { Pyloro- } \\
\text { duodenal }\end{array}$} & Prepyloric & $22(38.6 \%)$ & 22 & 0 \\
\hline & Duodenal (D1) & $28(49.1 \%)$ & 27 & 1 \\
\hline Gastric & & $7(12.2 \%)$ & 7 & 0 \\
\hline Total & & 57 & 56 & 1 \\
\hline
\end{tabular}

The study also found the presence of other factors in association with peptic ulcer perforation and affecting the healing in the postoperative period. The factors were the presence of preoperative symptoms of PUD, associated comorbidities, alcohol intake, smoking, chronic drug intake (NSAIDs/steroids), H. pylori infection and postoperative treatment (Table 5).

A correlation was established between the clinical and endoscopic findings for patients who were on postoperative antiulcer and $\mathrm{H}$. pylori eradication treatment at the end of follow-up of 6 months. The patients were categorized in four categories:

Group I: endoscopic active ulcer with symptoms;

Group II: endoscopic active ulcer without symptoms;

Group III: no ulcer and no symptoms; and

Group IV: nonulcer dyspepsia.

This is summarized in Table 6.

\section{Discussion}

Peptic perforation occurs in young and old patients all over the world. The incidence and prevalence of PUD have decreased in the last four decades in western countries but not in developing countries. Simple closure of perforated peptic ulcer with omental patch is quick and safe. ${ }^{4}$ Long-term follow-up of patient so treated shows that as many as $70 \%$ experience further ulcer symptoms and complications and $20-40 \%$ later require a definitive acid reducing operation. ${ }^{5}$ It is the morbidity that is a sequel of the perforated peptic ulcer that we have undertaken to evaluate clinically and endoscopically in this study.

\section{Age Incidence}

The highest incidence of patients with perforated peptic ulcer was found in the age group of 36-40 years in the present study. This is in accordance with the studies conducted by Mathur et al., ${ }^{6}$ Alegbeleye et al., ${ }^{7}$ Thorsen et al., ${ }^{8}$ and Svanes. ${ }^{9}$

Table 3: Summary of clinical findings at 8 weeks and 6 months postoperatively

\begin{tabular}{|c|c|c|c|c|c|c|}
\hline \multirow[b]{2}{*}{ Clinical category } & \multicolumn{3}{|c|}{8 weeks postoperatively } & \multicolumn{3}{|c|}{6 months postoperatively } \\
\hline & Taking $t / t$ & No $t / t$ & Total & Taking $t / t$ & No $t / t$ & Total \\
\hline Satisfactory well & 25 & 6 & 31 & 24 & 3 & 27 \\
\hline Mild dyspepsia & 15 & 8 & 23 & 14 & 10 & 24 \\
\hline Severe symptoms & - & 3 & 3 & 2 & 4 & 6 \\
\hline Total & 40 & 17 & 57 & 40 & 17 & 57 \\
\hline
\end{tabular}

Table 4: Summary of endoscopic findings at 8 weeks and 6 months postoperatively

\begin{tabular}{|c|c|c|c|c|c|c|c|}
\hline & & \multicolumn{3}{|c|}{8 weeks postoperatively } & \multicolumn{3}{|c|}{6 months postoperatively } \\
\hline \multicolumn{2}{|c|}{ Endoscopy findings } & Taking $t / t$ & Not/t & Total & Taking $t / t$ & No $t / t$ & Total \\
\hline 1 & Active duodenal ulcer & 3 & 6 & 9 & 5 & 1 & 6 \\
\hline 2 & Active pyloric ulcer & 3 & 1 & 4 & 4 & - & 4 \\
\hline 3 & Deformed bulb with scar & 1 & 1 & 2 & - & 2 & 2 \\
\hline 4 & Distorted bulb & 0 & 1 & 1 & - & 2 & 2 \\
\hline 5 & Stenosis & - & - & & 1 & - & 1 \\
\hline 6 & Gastritis/duodenitis & 2 & - & 2 & 2 & - & 2 \\
\hline 7 & Healing ulcer & 3 & - & 3 & 1 & - & 1 \\
\hline 8 & Retained suture & 4 & 1 & 5 & - & - & \\
\hline 9 & Scope not negotiable & - & 1 & 1 & - & 3 & 3 \\
\hline 10 & Normal & 24 & 6 & 30 & 27 & 9 & 36 \\
\hline Tot & & 40 & 17 & 57 & 40 & 17 & 57 \\
\hline
\end{tabular}




\begin{tabular}{|c|c|c|c|c|c|}
\hline \multicolumn{3}{|c|}{ Factors analyzed } & \multirow{2}{*}{ Active ulcer } & \multirow{2}{*}{$\frac{\text { Endoscopic normal/healed ulcer }}{6}$} & \multirow{2}{*}{$\begin{array}{l}\text { Total } \\
36\end{array}$} \\
\hline 1 & H/o PUD & Yes & & & \\
\hline & & No & 3 & 18 & 21 \\
\hline \multirow[t]{2}{*}{2} & Associated comorbidity & Present & 14 & 1 & 15 \\
\hline & & Absent & 19 & 23 & 42 \\
\hline \multirow[t]{2}{*}{3} & Alcohol intake & Present & 19 & 5 & 24 \\
\hline & & Absent & 14 & 19 & 33 \\
\hline \multirow[t]{2}{*}{4} & Smoking & Present & 25 & 9 & 34 \\
\hline & & Absent & 8 & 15 & 23 \\
\hline \multirow[t]{2}{*}{5} & Chronic drug intake & Present & 2 & 8 & 10 \\
\hline & & Absent & 31 & 16 & 47 \\
\hline \multirow[t]{2}{*}{6} & H. pylori infection & Present & 24 & 8 & 32 \\
\hline & & Absent & 9 & 16 & 25 \\
\hline \multirow[t]{2}{*}{7} & Postoperative treatment & Present & 16 & 24 & 40 \\
\hline & & Absent & 11 & 6 & 17 \\
\hline
\end{tabular}

Table 6: Correlation between overall clinical and endoscopic follow-up with comparison between postoperative treatment and no treatment group

\begin{tabular}{llcl}
\hline \multirow{2}{*}{ Group number } & \multicolumn{2}{c}{ Postoperative treatment } & \multirow{2}{*}{$\begin{array}{c}\text { Number of } \\
\text { patients (\%) }\end{array}$} \\
\cline { 2 - 3 } & Yes (\%) & No (\%) & \\
\hline I & $10(47.6)$ & $11(52.4)$ & $21(36.84)$ \\
II & $10(66.66)$ & $5(33.34)$ & $15(26.31)$ \\
III & $15(93.75)$ & $1(6.25)$ & $16(28.07)$ \\
IV & $5(100)$ & 0 & $5(8.7)$ \\
Total & $40(70.17)$ & $17(29.83$ & 57 \\
\hline
\end{tabular}

\section{Sex Incidence}

In this study, only one female patient was seen of age 25 years. A male preponderance is demonstrated in this study, which is in accordance with studies conducted by Svanes, ${ }^{9}$ Thorsen et al., ${ }^{8}$ and Jhobta et al. ${ }^{10}$ However, the number of female patients was too small to allow reliable comparison to be made.

\section{Distribution of Site of Ulcer Perforation}

Most of the times, it is difficult to ascertain the exact location of the perforation, so it is usually listed in various studies as juxtapyloric or pyloro-duodenal. In the present study, 50 patients (87.7\%) had pyloro-duodenal perforation and 7 (12.3\%) had gastric perforation. Results of the study by Mathur et al. ${ }^{6}$ also show an increase in the incidence of pyloro-duodenal perforation.

\section{Previous History of PUD}

It has been recognized for many years that patients with a long dyspeptic history are most likely to have ulcer after perforation. ${ }^{11}$ Peptic ulcers are classified based on duration of dyspepsia as acute and chronic, having duration more than 3 months. In a study by Patil, ${ }^{12} 60 \%$ patients had a previous history of PUD. In a study by Dongo et al., ${ }^{13} 43 \%$ patients had a history of PUD. In a study by Ghosh et al., ${ }^{14} 53 \%$ patients had a history of PUD. In the present study, $63 \%$ patients had a history of PUD.

\section{History of Associated Medical IIIness}

The comorbid condition of the patient complicates the episode of peptic perforation. In study by Bozkurtet al., ${ }^{15} 26.4 \%$ patients had comorbidities and resulted in postoperative complications in $24.2 \%$ patients. In the present study, 15 (26.3\%) patients had associated comorbid illness out of which 14 (93.4\%) patients had active ulcers after 6 months. Of the remaining 42 (73.7\%) patients who were not having any comorbid illness, only 19 (45.2\%) patients had active ulcers after 6 months, which is statistically significant $(p$ value $=0.003$ ) indicating a strong relationship between associated illness and postoperative ulcer healing.

\section{Relation with Alcohol/Smoking}

There is considerable evidence to suggest that both smoking and alcohol are associated with liability to perforation. A study by Asefa and Geyesus ${ }^{16}$ demonstrated history of smoking in $82.8 \%$ of their study population. Kamsir et al. ${ }^{17}$ provided definite conclusion regarding the relation between alcohol consumption and peptic ulcer perforation. Doll et al. ${ }^{18}$ and Svanes et al. ${ }^{9}$ have implicated in their respective studies that smoking is not only involved in the pathogenesis of peptic perforation and PUD but also that smokers have been found to have ulcers more frequently than nonsmokers. In the present study, a statistically significant result is obtained when comparing the active ulceration, 6 months postoperatively in the nonalcoholic and the nonsmoker group as against the alcoholic and smoker group ( $p$ value $=0.005$ and 0.003 , respectively).

\section{Relation with Chronic Drug Intake}

Chronic drug intake, especially NSAIDs plays a role in precipitating perforation. In various studies, the role of ulcerogenic drugs has been studied, such as NSAIDs and steroids. Ghosh et al. ${ }^{14}$ found $28.4 \%$ patients taking NSAIDs and 3.9\% patients taking NSAIDs and steroids in combination. Other studies by Zelickson et al. ${ }^{19}$ and Konturek et al. ${ }^{20}$ demonstrated $53 \%$ and $12.7 \%$ use of NSAIDs, respectively, by their study population. In the present study, 10 (17.5\%) patients were having drug-induced perforation out of which two patients had active ulcer at 6 months.

\section{Relation with $\mathrm{H}$. pylori Infection}

Over last 20 years, H. pylori infection has contributed significantly in the etiology of PUD. ${ }^{21,22}$ In a study by $\mathrm{Ng}$ et al., ${ }^{23} 61.8 \%$ had $H$. pylori infection and out of those, $48.93 \%$ demonstrated active ulcer at 6 months on endoscopy. Ghosh et al. ${ }^{14}$ demonstrated $H$. pylori infection in $72.5 \%$ of the study population. In the present study, H. pylori infection was observed in $32(56.14 \%)$ patients out of which 24 (75\%) patients had active ulcers after 6 months. 


\section{Postoperative Antiulcer Treatment}

In the present series, 40 patients were on postoperative antiulcer treatment out of whom 16 had active ulcer; and 24 had no ulcer postoperatively at 6 months. Among the rest 17 patients who were not antiulcer treatment, 11 had active ulcer and rest 6 had no ulcer. In a study by Gupta et al., ${ }^{24}$ all patients were given postoperative anti-H. pylori treatment and none had active ulcer at follow-up endoscopy. This dictates the use of postoperative treatment in the form of anti $H$. pylori regimen and antiulcer treatment. The Maastricht 5, 2016 Consensus Report also stated the routine use of anti-H. pylori regimen as a must for all cases of complicated PUD. ${ }^{25}$

\section{Conclusion}

Peptic ulcer disease leading to perforation peritonitis is seen in middle-aged men in the age group of 35-40 years. The closure of perforation with an omental patch is relatively quick and simple measure (Graham's patch repair), but these patients may require further definitive surgery for PUD depending upon symptomatology and lifestyle. Postoperative treatment with $\mathrm{H} 2$ blockers or proton pump inhibiters along with anti-H. pylori regimen should be prescribed for all such patients. Routine endoscopic examination of such patients should also form a part of the follow-up to look for ulcer healing postoperatively. While smoking and alcohol are independent risk factors in the etiology of PUD, they also determine ulcer healing in such patients in the postoperative period and so advice should be given, at the time of discharge, about deaddiction. There is a change in the trend of the management of peptic ulcer perforation with the advent of newer and less invasive techniques, such as laparoscopic or endoscopic perforation sealing technique. A multidisciplinary approach for perforated peptic ulcer management is of utmost importance and help in early recovery of the patient.

\section{Ethical Committee Approval}

Proper Ethical Committee Approval was taken for the study.

\section{References}

1. Cucino C, Sonnenberg A. The long-term time trends of peptic ulcer and ulcerative colitis are interrelated. Am J Gastroenterol 2002;97(10):2657-2662. DOI: 10.1111/j.1572-0241.2002.06045.x.

2. Ramakrishnan K, Salinas RC. Peptic ulcer disease. Am Fam Physician 2007;76(7):1005-1012.

3. Cocks JR. Perforated peptic ulcer-the changing scene. Dig Dis 1992;10(1):10-16. DOI: 10.1159/000171339.

4. Mouly C, Chati R, Scotte M, et al. Therapeutic management of perforated gastro-duodenal ulcer: literature review. J Visc Surg 2013;150(5):333-340. DOI: 10.1016/j.jviscsurg.2013.07.001.

5. Ceneviva R, Modena JP, Silva O, et al. Simple suture with or without proximal gastric vagotomy for perforated duodenal ulcer. Br J Surg 1986;73(6):424-430. DOI: 10.1002/bjs.1800730604.
6. Mathur PN, Kumawat JL, Joshi CP, et al. Retrospective study of perforated peptic ulcer: a surgical emergency. Int Surg J 2017;4(1): 19-23. DOI: 10.18203/2349-2902.isj20163979.

7. Alegbeleye BJ. A modified open omental plugging of peptic ulcer perforation in a mission hospital, Northwestern Cameroon. J Clin Invest Stud 2019;2(1):1-9. DOI: 10.15761/JCIS.1000119.

8. Thorsen K, Glomsaker TB, von Meer A, et al. Trends in diagnosis and surgical management of patients with perforated peptic ulcer. J Gastrointest Surg 2011;15(8):1329-1335. DOI: 10.1007/s11605-011-1482-1.

9. Svanes C. Trends in perforated peptic ulcer: incidence, etiology, treatment and prognosis. World J Surg 2000;24(3):277-283. DOI: $10.1007 / \mathrm{s} 002689910045$.

10. Jhobta RS, Attri AK, Kaushik R, et al. Spectrum of perforation peritonitis in India-review of 504 consecutive cases. World J Emerg Surg 2006;1:26. DOI: 10.1186/1749-7922-1-26.

11. Illingworth $C F$, Scott LD, Jamieson RA. Progress after perforated peptic ulcer. Br Med J 1946;1(4455):787-790. DOI: 10.1136/bmj.1.4455.787.

12. Patil R, Kamthane S, Reddy PA. A study of duodenal ulcer perforation: risk factors and prognostic determinants in Gulbarga. J Evol Med Dent Sci 2015;4(91):15657-15664. DOI: 10.14260/jemds/2015/2252.

13. Dongo AE, Uhunmwagho $\mathrm{O}$, Kesieme EB, et al. A five-year review of perforated peptic ulcer disease in Irrua, Nigeria. Int Sch Res Notices 2017;2017:8375398. DOI: 10.1155/2017/8375398.

14. Ghosh BC, Gangopadhyay A, Ghosh G. Assessment of recent epidemiological trends in peptic ulcer perforation patients in an eastern Indian tertiary hospital. Asian J Med Sci 2018;9(6):68-75. DOI: 10.3126/ajms.v9i6.20858.

15. Kocer B, Sumeli S, Solak C, et al. Factors affecting mortality and morbidity in patients with peptic ulcer perforation. J Gastroenterol Hepatol 2007;22(4):565-570. DOI: 10.1111/j.1440-1746.2006.04500.x.

16. Asefa Z, Geyesus A. Perforated peptic ulcer disease in Zewditu Hospital. Ethiop Med J 2012;50(2):145-151.

17. Kamsir K, Asrul A, Muradi A. Characteristic of gastric perforation type and the histopathology at Haji Adam Malik General Hospital MedanIndonesia. Bali Med J 2016;5(1):186-188. DOI: 10.15562/bmj.v5i1.325.

18. Doll $R$, Peto $R$, Wheathly $K$, et al. Mortality in relation to smoking: 40 years' observations on male British doctors. BMJ 1994;309(6959): 901-911. DOI: 10.1136/bmj.309.6959.901.

19. Zelickson MS, Bronder CM, Johnson BL, et al. Helicobacter pylori is not the predominant etiology for peptic ulcers requiring operation. Am Surg 2011;77(8):1054-1060.

20. Konturek SJ, Bielaoski W, Płonka M, et al. Helicobacter pylori, nonsteroidal anti-inflammatory drugs and smoking in risk pattern of gastro duodenal ulcers. Scand J Gastroenterol 2003;38(9):923-930. DOI: 10.1080/00365520310004696.

21. Sivri B. Trends in peptic ulcer pharmacotherapy. Fundam Clin Pharmacol 2004;18(1):23-31. DOI: 10.1111/j.1472-8206.2004.00203.x.

22. Ahmed N.23years of the discovery of Helicobacterpylori: is the debate over? Ann Clin Microbiol Antimicrob 2005;4:17. DOI: 10.1186/1476-0711-4-17.

23. Ng EK-W, Leung W-K, To K-F, et al. The role of early endoscopic follow up after simple closure of perforated duodenal ulcer: a prospective study. Ann Coll Surg Hong Kong 2002;6(3):71-76. DOI: 10.1046/j.14422034.2002.00136.x.

24. Gupta BS, Talukdar RN, Neupane HC. Cases of perforated duodenal ulcer treated in College of Medical Sciences, Bharatpur over a period of one year. Kathmandu Univ Med J (KUMJ) 2003;1(3):166-169.

25. Management of Helicobacter pylori infection - the Maastricht V/ Florence Consensus Report. 